\title{
Identification and characterization of microRNAs in white and brown alpaca skin
}

Xue Tian ${ }^{1}$, Junbing Jiang ${ }^{1}$, Ruiwen Fan ${ }^{1}$, Haidong Wang ${ }^{1}$, Xiaolin Meng ${ }^{1}$, Xiaoyan He${ }^{1}$, Junping He ${ }^{1}$, Hongquan $\mathrm{Li}^{1}$, Jianjun Geng ${ }^{1}$, Xiuju Yu ${ }^{1}$, Yunfei Song ${ }^{1}$, Danli Zhang ${ }^{1}$, Jianbo Yao ${ }^{1,2}$, George W Smith ${ }^{1,3}$ and Changsheng Dong ${ }^{1 *}$

\begin{abstract}
Background: MicroRNAs (miRNAs) are small, non-coding 21-25 nt RNA molecules that play an important role in regulating gene expression. Little is known about the expression profiles and functions of miRNAs in skin and their role in pigmentation. Alpacas have more than 22 natural coat colors, more than any other fiber producing species. To better understand the role of miRNAs in control of coat color we performed a comprehensive analysis of miRNA expression profiles in skin of white versus brown alpacas.
\end{abstract}

Results: Two small RNA libraries from white alpaca (WA) and brown alpaca (BA) skin were sequenced with the aid of Illumina sequencing technology. 272 and 267 conserved miRNAs were obtained from the WA and BA skin libraries, respectively. Of these conserved miRNAs, 35 and 13 were more abundant in WA and BA skin, respectively. The targets of these miRNAs were predicted and grouped based on Gene Ontology and KEGG pathway analysis. Many predicted target genes for these miRNAs are involved in the melanogenesis pathway controlling pigmentation. In addition to the conserved miRNAs, we also obtained 22 potentially novel miRNAs from the WA and BA skin libraries.

Conclusion: This study represents the first comprehensive survey of miRNAs expressed in skin of animals of different coat colors by deep sequencing analysis. We discovered a collection of miRNAs that are differentially expressed in WA and BA skin. The results suggest important potential functions of miRNAs in coat color regulation.

Keywords: Alpaca, MicroRNAs, Deep sequencing, Coat color, Skin

\section{Background}

Since the first small RNA (sRNA) - lin4 was discovered in C. elegans, identification of small endogenous noncoding RNA (sncRNA) has received considerable attention. SncRNAs include small interfering RNA [1], miRNA [2] and piwi-interacting RNA, which all regulate genes at the post-transcriptional level [3]. Among these sncRNAs, miRNAs are small, non-coding 21-25 nt RNA molecules that play an important role in regulating gene expression in animals and plants by promoting mRNA degradation and inhibiting mRNA translation [4]. However, other studies revealed that some miRNAs may also function to induce gene expression [5]. Many miRNAs are evolutionary conserved in related species and some even show conservation between invertebrates and

\footnotetext{
* Correspondence: cs_dong@sxau.edu.cn

${ }^{1}$ College of Animal Science and Technology, Shanxi Agricultural University,

Taigu 030801, People's Republic of China

Full list of author information is available at the end of the article
}

vertebrates [6]. Generally, the functions of miRNAs are not limited to the regulation of developmentally timed events. Instead, they have diverse expression patterns and probably regulate many aspects of development and physiology [7]. To date, the miRBase database contains 9072 mature miRNA products from 25 mammalian species. Recently, transcriptome profiling of miRNAs has led to identification of novel miRNAs, provided valuable information on tissue specific expression and evolutionary conservation across species, and served as a cornerstone for subsequent functional analyses.

In adult animals, both hair and skin color depend on pigment produced by melanocytes at the base of the epithelium [8]. Melanocytes in mammals and birds produce two types of melanin, black to brown eumelanin and yellow to reddish brown pheomelanin $[9,10]$. The quality and ratio of eumelanin to pheomelanin influence the color of skin, fleece and eyes [9]. At present, a large number of genes have been found to affect hair and skin 
color in humans and other vertebrate species [11-13], although the molecular and cellular mechanisms regulating coat color in fiber-producing species, such as the alpaca, are not completely understood.

Alpacas have a great variety of natural coat colors. Studies of the melanocortin-1 receptor (MC1R) and agouti signaling protein (ASIP) genes in alpacas of different coat colors revealed several polymorphisms that may be predictive of coat color [14-18]. Powell et al. reported that the M87V and S126G variants of MC1R may affect coat color with brown coat color animals showing homozygosity for the methionine and serine alleles [16]. Tyrosinase related protein 1 (TYRP1) is encoded by the brown locus and is involved in eumelanin synthesis [19]. Mutations in TYRP1 are associated with brown coat color in many species [20,21], but mutations in TYRP1 associated with brown coat color in alpacas have not been reported to date. Previous studies in our laboratory revealed that the expression of many coat color genes including MC1R, TYRP1, tyrosinase (TYR), tyrosinase related protein 2 (TYRP2), nitric oxide synthase 2 (NOS2), paired box protein 3 (PAX3), and WNT3A was higher in skin of brown versus white alpacas, suggestive of a functional contribution to coat color regulation in this species. However, the potential contribution of miRNAs to differential expression (associated with coat color) of such genes has not been fully elucidated, primarily due to a lack of knowledge of the miRNA transcriptome profile in alpaca skin.

Previous studies have addressed expression and function of miRNAs in mouse, goat and sheep skin [22-25]. For example, miR-203, a skin specific miRNA, was up-regulated in psoriatic plaques and shown to be involved in inflammatory responses and keratinocyte functions [26]. However, studies of the functional role of miRNAs in coat color regulation are limited. Dong et al. over-expressed miR-137 in mice and obtained a series of coat color changes in transgenic animals [27]. Zhu et al. reported differential

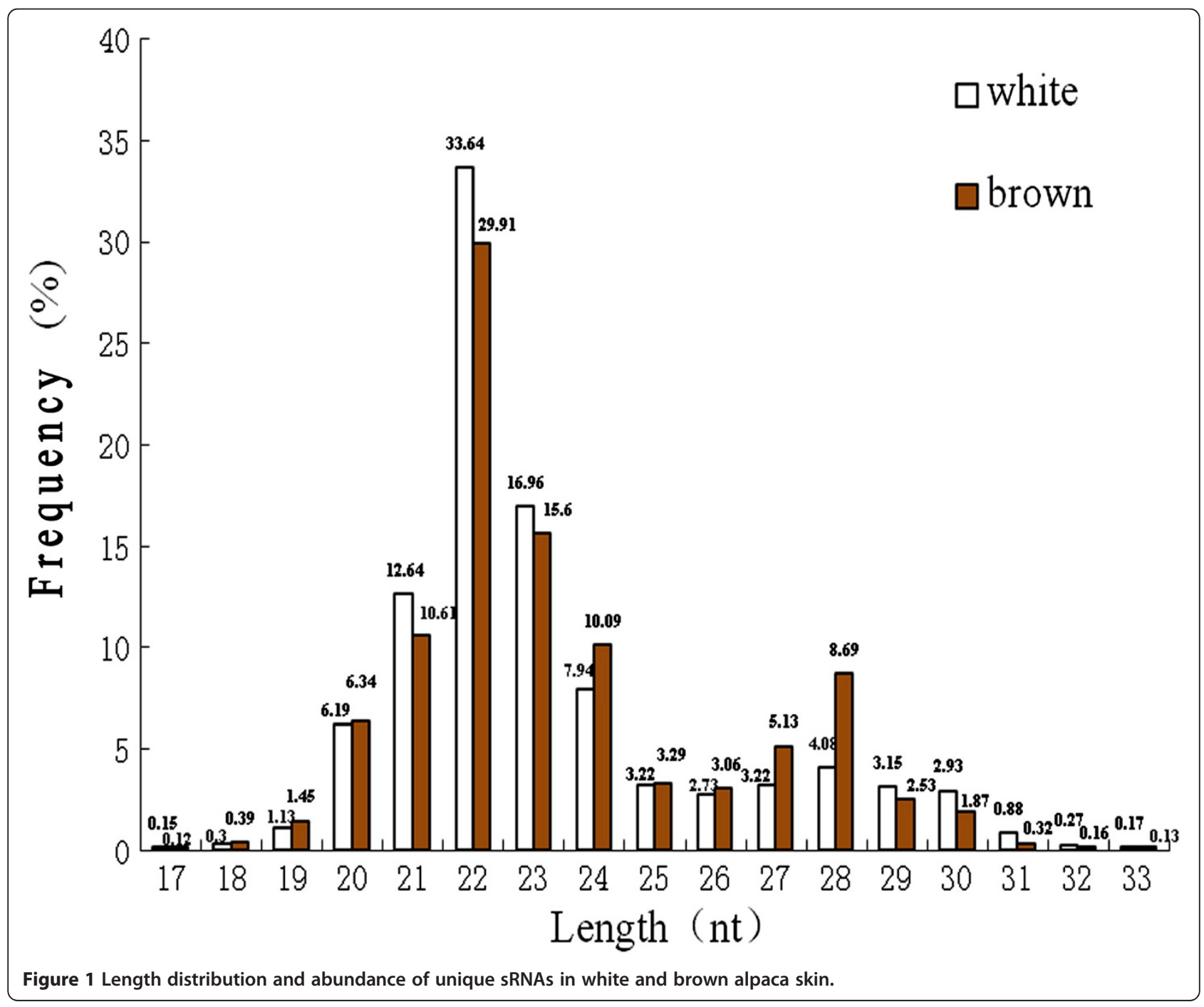


expression of miR-25 in skin of white versus brown alpacas and a functional role of this miRNA in the regulation of expression of microphthalmia-associated transcription factor (MITF), a transcription factor regulating expression of key genes involved in melanogenesis [28].

To better understand the potential role of miRNAs in the post-transcriptional regulation of genes linked to pigmentation, we have characterized the miRNA transcriptome in skin of alpaca of different coat colors by deep sequencing analysis. We report here the identification of hundreds of conserved miRNAs and candidate novel miRNAs in WA and BA skin. We also provide evidence of differential expression of miRNAs in WA and $\mathrm{BA}$, foundational to future studies of the potential functional role for such miRNAs in post-transcriptional gene regulation linked to coat color.

\section{Results \\ Overall complexity of sRNA pools between the WA and BA skin libraries}

To identify miRNAs expressed in alpaca skin, WA and BA skin small RNA libraries were analyzed by deep sequencing. A total of 17,427,359 and 19,748,517 raw reads were obtained from WA and BA libraries respectively. After filtering out the low quality reads based on base quality value and removing adaptor sequences, $16,834,090$ (98.42\%) and 19,069,600 (98.49\%) clean reads were retrieved, corresponding to $1,058,335$ and 977,308 unique sequences, which were the associated counts of the identical sequence reads, respectively. The length distribution of sRNA reads is shown in Figure 1. The majority of the sRNAs were 21-24 nt in length, which is characteristic of sRNAs from metazoans. The most frequent length of sRNA sequenced was 22nt, which is identical to the classical size of Dicer cleavage products.

The alpaca genome has been completely sequenced, but at low coverage and is not well annotated. Thus, the alpaca (http://www.ncbi.nlm.nih.gov) and Bos taurus genome databases (http://www.ncbi.nlm.nih.gov/nuccore/) were combined and used as a reference genome dataset for annotation of alpaca sRNAs. The total sRNA reads were mapped to the combined genome using the SOAP program, yielding 10,389,135 (61.71\%) and 12,630,855 (66.24\%) genome matched reads in WA and BA libraries, respectively. In order to annotate the classes of all sRNAs, all clean reads were mapped using several databases, including GenBank, Rfam, animal miRNAs (miRBase), exon and intron (Bos taurus) and repeat associated RNA. The representations of different types of sRNAs in WA and BA libraries are shown in Figure 2. By aligning the sRNAs to all known animal miRNA precursors, $3820 \quad(6,527,628$ total reads) and 3823 $(7,583,101$ total reads) unique sequences were identified as potentially conserved miRNA in WA and BA skin, respectively.

\section{Identification of conserved miRNAs in alpaca skin}

To further identify conserved miRNAs in alpacas, all sRNA sequences were mapped to known miRNAs in the miRBase 17.0 database. After alignment and additional sequence analysis, 272 and 267 individual candidate miRNAs from WA and BA skin libraries were identified, respectively. Approximately 155 miRNA families were represented in each library. Several miRNA families were represented by over 100,000 reads, such as Let-7, miR146, miR-143, miR-21, miR-10, miR-378, miR-182, miR8 , and miR-30, which were the 9 most abundant miRNA families represented in WA and BA libraries (Figure 3). The read diversity of miRNA families indicated that different miRNA families have different expression patterns. Besides the diversity in miRNA families, there was considerable variation in number of miRNA family members represented across families. For example, 13 and 12 miR-154 family members were represented in WA and BA libraries, whereas many miRNA families only had 1 to 2 members (Figure 4).

\section{Differential expression of conserved miRNAs in white and brown alpaca skin}

In high throughput sequencing analysis, the number of reads is reflective of the expression level of miRNAs. Many conserved miRNAs exhibited dissimilar expression patterns in WA versus BA skin. There were 35 miRNAs showing markedly greater abundance in WA skin, and 13 miRNAs more highly expressed in BA skin (Table 1 ). For example, miR-202, miR-542-5p, miR-424, miR-370 and miR-22-3p were more abundantly expressed in WA skin, while miR-211, miR-184, miR-486, miR-885 and miR-451 were more highly expressed in BA skin. In order to validate the deep sequencing results, $10 \mathrm{miR}$ NAs were selected to determine their expression levels in white and brown alpaca skin by real time PCR. The results of real time PCR analysis confirmed the deep sequencing results (Figure 5). For example, based on deep sequencing results, the expression level of miR-211 in WA was almost 20 times higher than observed in BA. Based on real time PCR results, the expression level of miR-211 in WA skin was also 13 times higher than observed in BA skin.

\section{Sequence divergence within known miRNAs}

The heterogeneity across sequenced reads at the 5 and 3' ends from the same arms within individual known miRNAs detected were also analyzed. The 5' ends exhibited less heterogeneity than the 3' ends. For instance, miR-29c, miR-362-5p, and miR-222 were highly represented and sequenced from the two libraries. The 


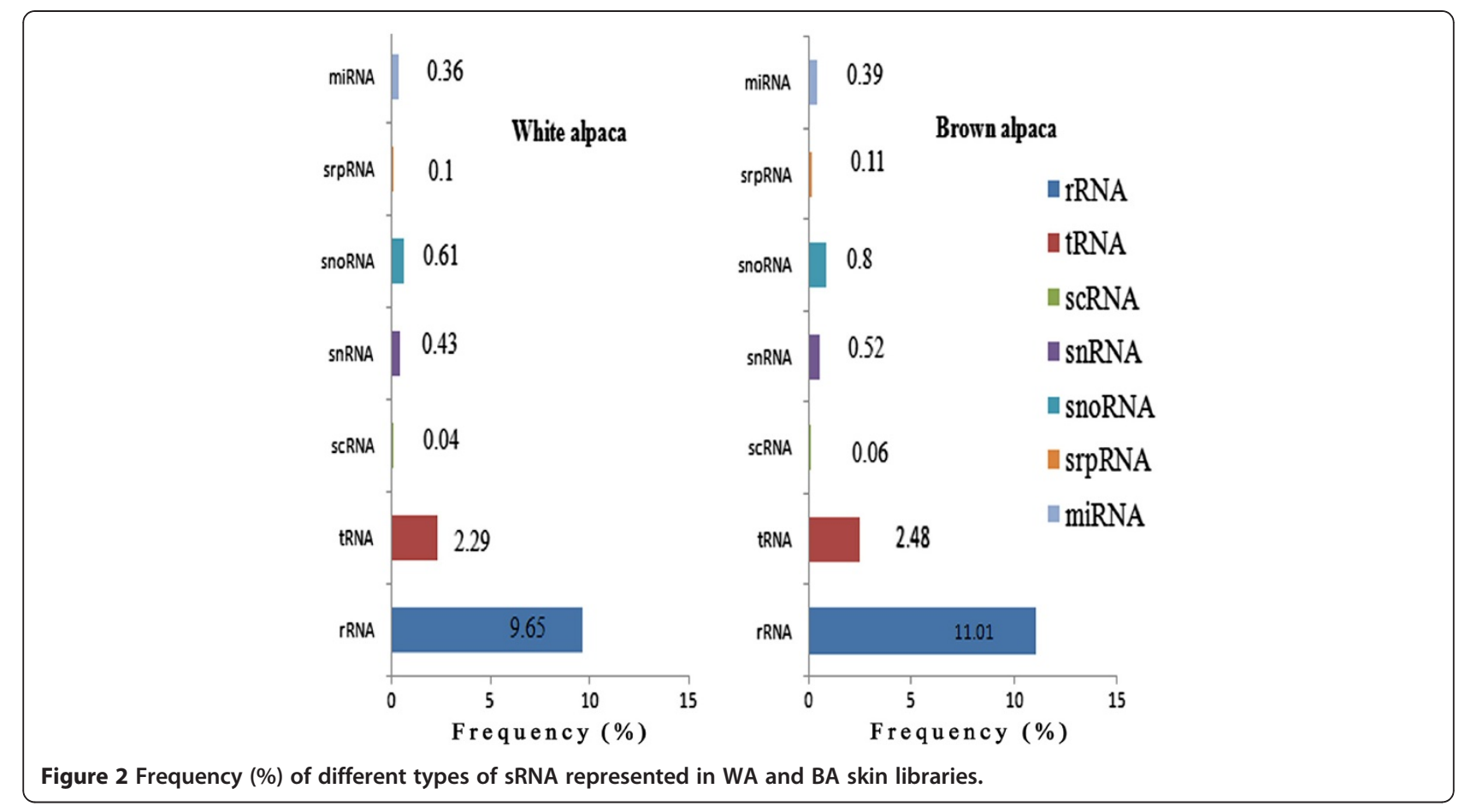

predominant reads for these miRNAs obtained from deep sequencing data varied from the mature miRNA sequences in miRBase at the 3' end, and they should be regarded as the primary functional molecule (Figure 6). Collectively from the two libraries, the 5' and 3' end of 109 alpaca miRNAs were different in sequence from corresponding annotated miRNAs for each species in

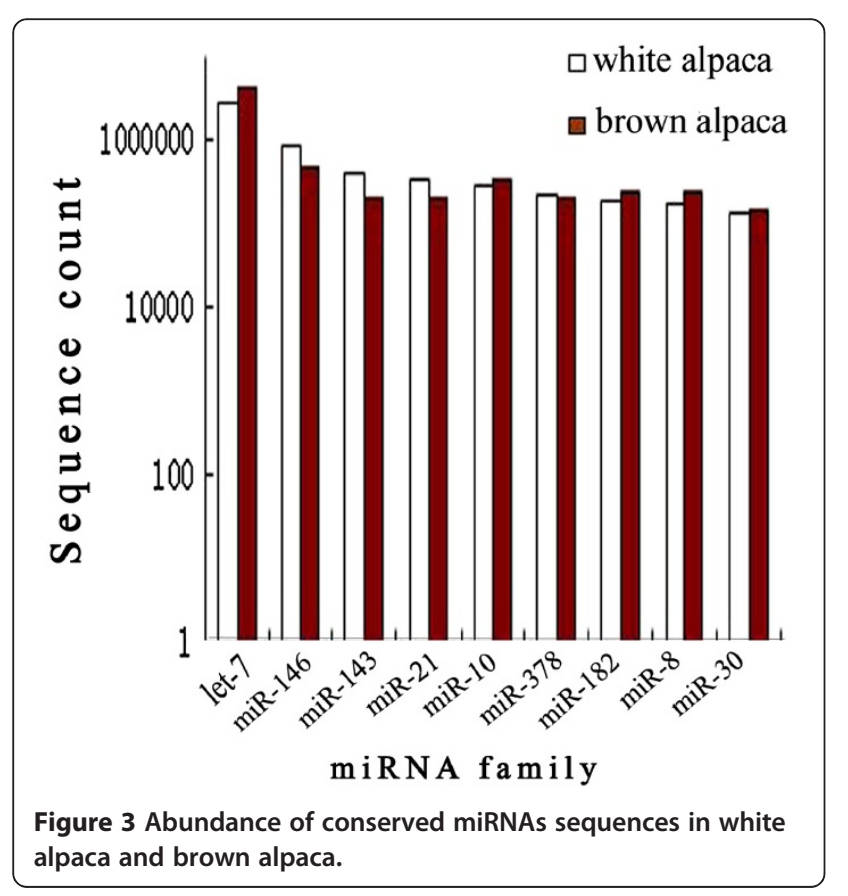

miRBase (Additional file 1). Furthermore, several abundant miRNAs with higher sequencing reads, like miR30a, miR-324 and miR-330, were derived from different arms of the hairpin precursor than corresponding annotated miRNAs in miRBase (Figure 7). Thus, results suggest that the precursors of these miRNAs develop functional molecules from both arms in the alpaca.

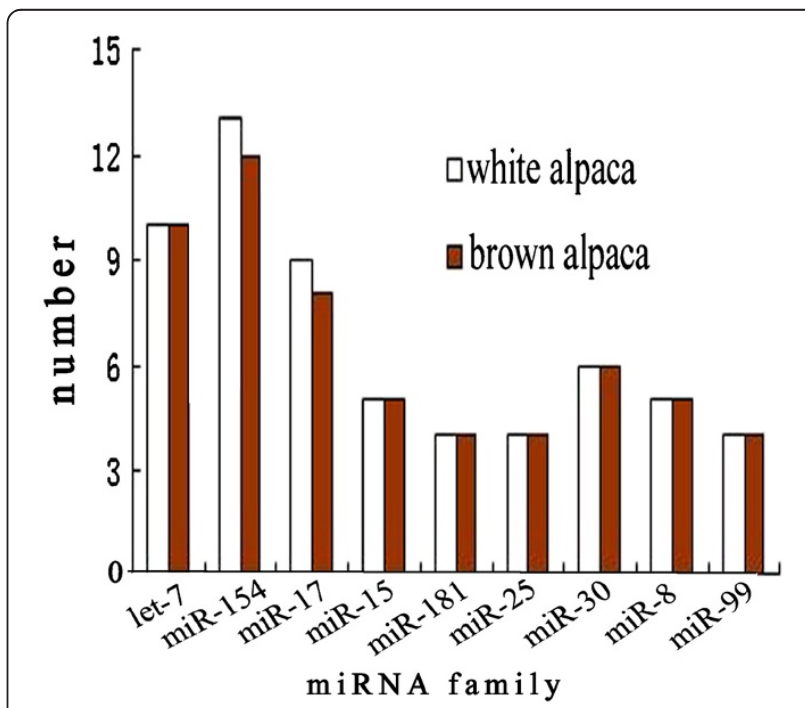

Figure 4 Number of members in different miRNA families in white alpaca and brown alpaca skin. 
Table 1 Significantly expressed miRNAs in white and brown alpaca skin

\begin{tabular}{|c|c|c|c|}
\hline miR-name & NEL in brown & NEL in white & FC \\
\hline \multicolumn{4}{|l|}{ White alpaca } \\
\hline miR-202 & 1.9927 & 95.2234 & 47.7861 \\
\hline miR-424* & 0.1573 & 1.6633 & 10.5741 \\
\hline miR-542-5p & 0.3146 & 2.8514 & 9.0636 \\
\hline miR-424 & 3.2512 & 25.1870 & 7.7470 \\
\hline miR-370 & 0.5244 & 3.6236 & 6.9100 \\
\hline miR-22-3p & 207.9226 & 1354.8698 & 6.5162 \\
\hline miR-27a-3p & 71.6323 & 429.4856 & 5.9957 \\
\hline miR-450 & 2.0976 & 12.0589 & 5.7489 \\
\hline miR-34c & 11.3794 & 56.1955 & 4.9383 \\
\hline miR-122 & 5.9781 & 28.0977 & 4.7001 \\
\hline miR-136 & 0.3146 & 1.2475 & 3.9653 \\
\hline miR-493 & 0.8915 & 3.2672 & 3.6648 \\
\hline miR-216a & 2.9366 & 10.0986 & 3.4389 \\
\hline miR-671 & 2.0976 & 6.8908 & 3.2851 \\
\hline miR-494 & 1.0488 & 3.0890 & 2.9452 \\
\hline miR-190a & 4.2476 & 11.7024 & 2.7551 \\
\hline miR-18a & 4.2476 & 11.5836 & 2.7271 \\
\hline miR-124a & 0.7866 & 2.1385 & 2.7187 \\
\hline miR-124b & 0.7866 & 2.1385 & 2.7187 \\
\hline miR-148a & 1653.0499 & 4265.9865 & 2.5807 \\
\hline miR-206 & 2.7269 & 6.8908 & 2.5270 \\
\hline miR-204 & 1.8354 & 4.6335 & 2.5245 \\
\hline miR-369-3p & 3.4610 & 8.7323 & 2.5231 \\
\hline miR-345-3p & 1.6256 & 4.0394 & 2.4849 \\
\hline miR-193a-3p & 0.5768 & 1.4257 & 2.4718 \\
\hline miR-874 & 0.8915 & 2.1385 & 2.3988 \\
\hline miR-19a & 2.3073 & 5.4057 & 2.3429 \\
\hline miR-143 & 10818.3706 & 24308.7093 & 2.2461 \\
\hline miR-1296 & 1.4683 & 3.2672 & 2.2252 \\
\hline miR-210 & 3.6708 & 7.9006 & 2.1523 \\
\hline miR-301a & 0.839 & 1.7821 & 2.1241 \\
\hline miR-27a-5p & 55.009 & 112.8662 & 2.0518 \\
\hline miR-146b & 25987.7501 & 53201.0343 & 2.0472 \\
\hline miR-200a & 79.708 & 162.1709 & 2.0346 \\
\hline miR-17-3p & 3.9854 & 8.0788 & 2.0271 \\
\hline \multicolumn{4}{|c|}{ Brown alpaca } \\
\hline miR-211 & 47.4053 & 2.9108 & 16.2860 \\
\hline miR-184 & 232.0447 & 22.2762 & 10.4167 \\
\hline miR-486 & 983.9221 & 151.6565 & 6.4878 \\
\hline miR-885 & 5.1915 & 0.9505 & 5.4619 \\
\hline miR-451 & 1122.4147 & 411.0706 & 2.7305 \\
\hline miR-133a & 4.1427 & 1.6039 & 2.5829 \\
\hline miR-299 & 1.7829 & 0.7128 & 2.5013 \\
\hline miR-23a & 708.5623 & 304.5606 & 2.3265 \\
\hline miR-25 & 504.2581 & 226.8017 & 2.2233 \\
\hline
\end{tabular}

Table 1 Significantly expressed miRNAs in white and brown alpaca skin (Continued)

\begin{tabular}{llll}
\hline miR-23b-3p & 823.9292 & 371.211 & 2.2196 \\
\hline miR-1224 & 6.6598 & 3.0296 & 2.1982 \\
\hline miR-15b & 121.5547 & 58.5716 & 2.0753 \\
\hline miR-193b & 207.1360 & 100.4509 & 2.0620 \\
\hline
\end{tabular}

Nel, normalized expression level of miRNA in a sample; FC, fold change of miRNAs between white and brown alpaca skin; $\mathrm{Nel}=$ actual miRNA count/total count of clean reads $\times 1000000$.

\section{Target gene prediction for miRNAs in alpaca}

MiRNAs have functions in numerous developmental, physiological and pathological processes [29]. In order to provide insight into potential biological roles of miRNAs identified in alpaca skin, target prediction analysis was performed for alpaca skin miRNAs identified. The rules employed for target prediction were based on those reported by Allen et al. [30] and Schwab et al. [31]. There were 6317 genes predicted as the putative targets of conserved miRNAs in WA (272 miRNAs) and BA (267 miRNAs) skin, respectively. The predicted target genes were then subjected to gene ontology analysis for functional classification. Although the target functions of miRNA in WA and BA skin had some divergence, the top functions of targets were binding, transferase activity, molecular transducer activity, and receptor activity (Additional file 2). The KEGG pathway was also used to further classify putative miRNA targets. All predicted targets were clustered into 257 pathways in WA and BA, respectively. Results were then interrogated for potential target genes implicated in coat color regulation and the melanogenesis pathway. Many genes in the melanogenesis pathway have already been shown to have a relationship with coat color in alpaca [32-35], such as pro-opiomelanocortin (POMC), melanocyte-stimulating hormone (MSH), MITF, kit oncogene (KIT) and TYR. Moreover, several miRNAs whose targets are involved in melanogenesis were expressed differentially in WA and BA skin. The target genes for the top 4 significantly expressed miRNAs in WA and BA included in the melanogenesis pathway are shown in Table 2.

\section{Identification of novel miRNAs in alpaca skin}

Because the alpaca genome has not been annotated, the bovine genome was utilized to identify potential novel miRNAs. It is well known that the important feature of miRNAs distinguishing them from other small RNAs is the ability of their genomic flanking sequences to fold into a hairpin structure [36]. The Mireap software was used to predict novel miRNAs using these properties. After filtering, 88 and 94 sequencing reads from WA and BA skin remained. Blast analysis against all mature miRNAs in miRBase, revealed 55 miRNAs from WA 


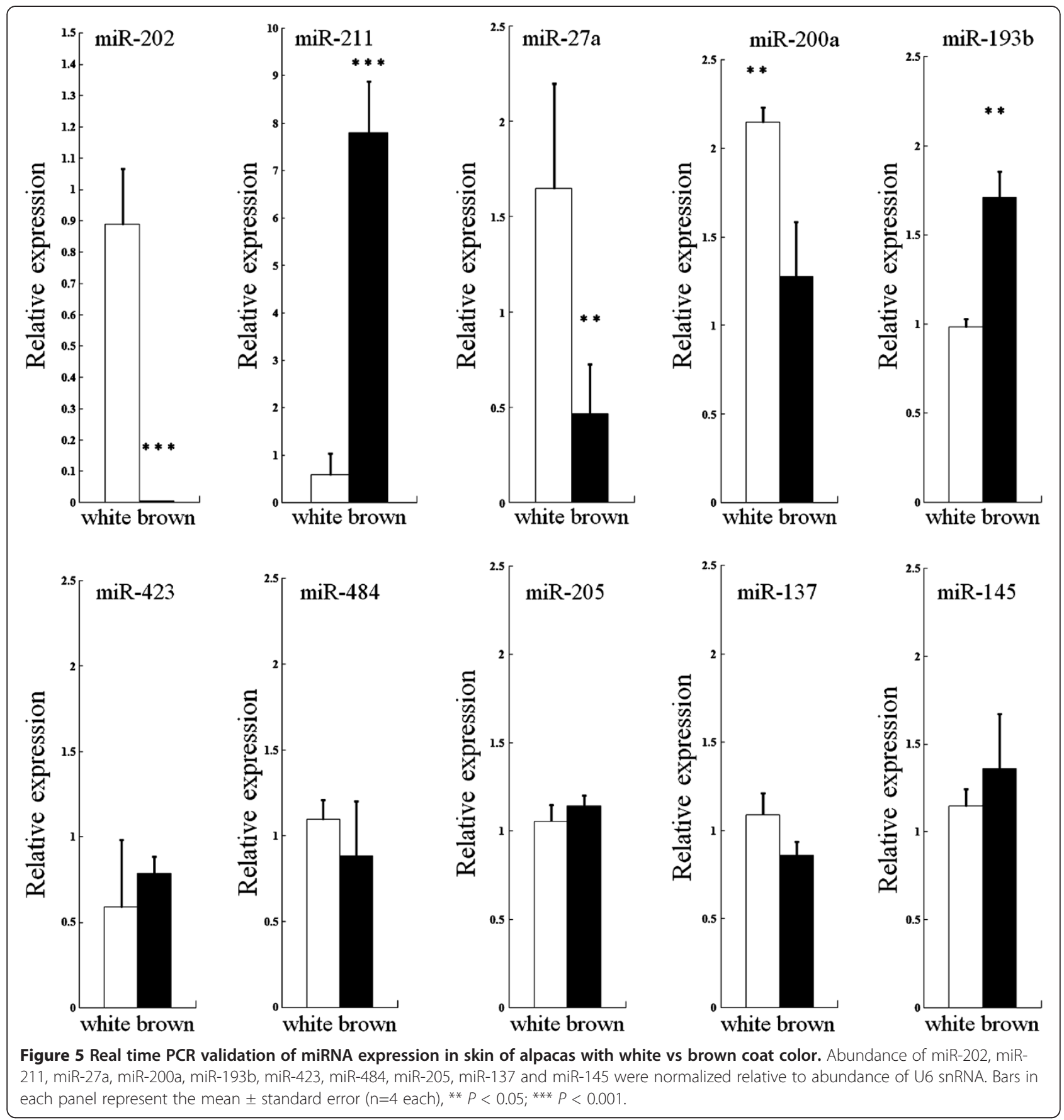

and 63 miRNAs from BA libraries that had no homology with other species. In these novel miRNAs, 31 miRNAs were common between WA and BA libraries. Thus, a total of 87 unique novel miRNAs were identified (Additional file 3). The hairpin structures for these novel miRNAs were denoted in Additional file 4. The lengths of these novel miRNAs ranged from 21 to 24nt, and the minimum free energy (MFE) of the novel miRNAs varied from -55.90 to $-19.00 \mathrm{kcal} \mathrm{mol}^{-1}$. The average MFE of novel miRNAs was $-34.83 \mathrm{kcal} \mathrm{mol}^{-1}$, which is lower than tRNA and rRNA. This result was similar to results of Bonnet et al. [37] indicating that the majority of miRNAs exhibit a folding free energy which is lower than shuffled sequences. To further identify genuine miRNAs, the length of the RNAs was also considered. The MFE index (MFEI) was used to reevaluate the potential novel miRNAs identified. Zhang et al. suggested that the MFEI for miRNAs was 0.97, significantly higher than tRNAs, rRNAs or mRNAs [38]. The MFEI of the 87 potential novel miRNAs ranged from 


\begin{tabular}{|c|c|c|c|c|c|c|}
\hline \multicolumn{7}{|l|}{$\operatorname{miR}-29 \mathrm{c}$} \\
\hline \multicolumn{7}{|c|}{ 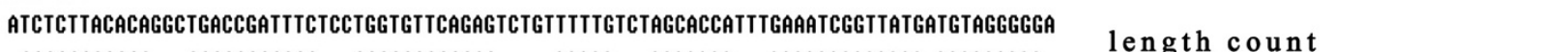 } \\
\hline \multirow{2}{*}{\multicolumn{3}{|c|}{ 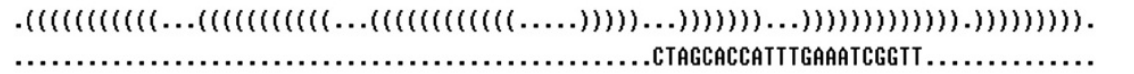 }} & \multicolumn{4}{|c|}{ length count } \\
\hline & & & 22 & 2 & & \\
\hline \multicolumn{3}{|c|}{ 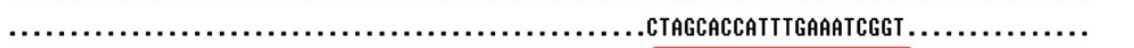 } & 21 & 2 & & \\
\hline \multicolumn{3}{|c|}{ 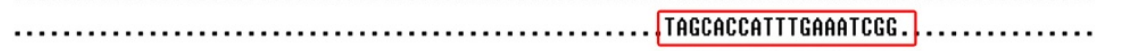 } & 19 & 70 & & \\
\hline \multicolumn{3}{|c|}{ 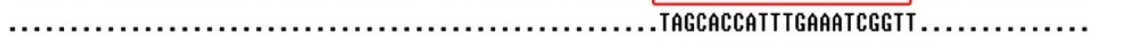 } & 21 & 61 & & \\
\hline \multicolumn{3}{|c|}{ 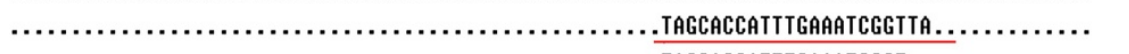 } & 22 & 49 & & \\
\hline \multicolumn{3}{|c|}{. } & 20 & 42 & & \\
\hline \multicolumn{3}{|c|}{ 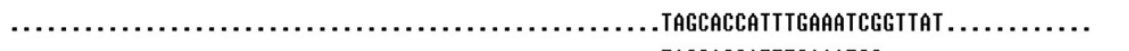 } & 23 & 3 & & \\
\hline \multicolumn{3}{|c|}{ 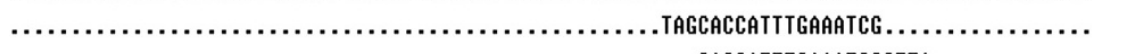 } & 18 & 1 & & \\
\hline \multicolumn{3}{|c|}{ 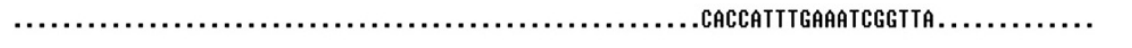 } & 19 & 1 & & \\
\hline \multicolumn{7}{|l|}{$\operatorname{miR}-362-5 p$} \\
\hline \multicolumn{7}{|l|}{ СTCGAATCCTTGGAACCTAGGTGTGAGTGCTGTTCTAGTGCAACACACСTATTCAAGGATTCAAA } \\
\hline 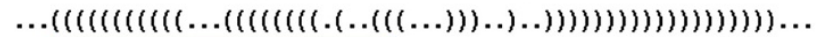 & length & $\operatorname{count}$ & & & & \\
\hline 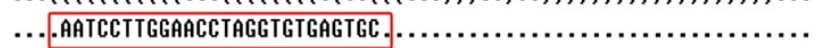 & 26 & 249 & & & & \\
\hline 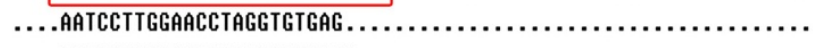 & 23 & 50 & & & & \\
\hline 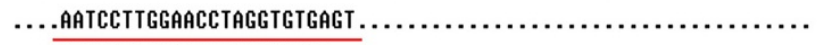 & 24 & 29 & & & & \\
\hline .... & 22 & 21 & & & & \\
\hline 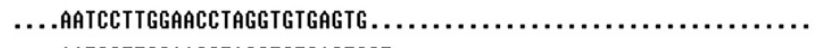 & 25 & 4 & & & & \\
\hline 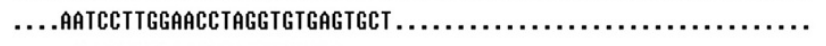 & 27 & 2 & & & & \\
\hline 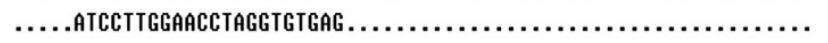 & 22 & 1 & & & & \\
\hline 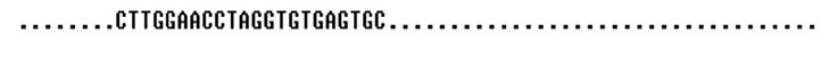 & 22 & 2 & & & & \\
\hline \multicolumn{7}{|l|}{ miR-222 } \\
\hline \multicolumn{7}{|c|}{ 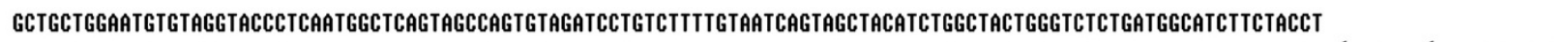 } \\
\hline \multicolumn{6}{|c|}{ 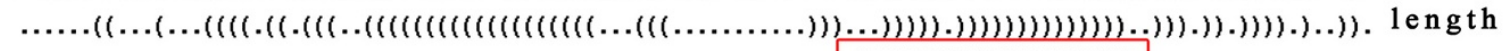 } & count \\
\hline \multirow{2}{*}{\multicolumn{5}{|c|}{. }} & 23 & 316 \\
\hline & & & & & 25 & 219 \\
\hline 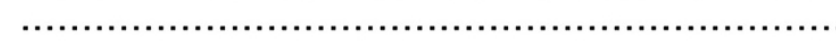 & . AGCTACATCTG & gGCTACTgGgtcto & & ......... & 24 & 181 \\
\hline 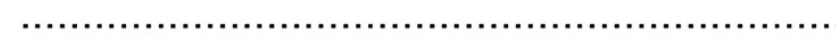 & . AGCTACATCTG & GGCTACTGGG... & ............ & ......... & 21 & 133 \\
\hline & . AGCTACATCTG & gGCTACTGGG.... & ............ & $\ldots \ldots \ldots$ & 20 & 74 \\
\hline n.m. & .АGCTACAтCTG & gGCTACTgGgtc. & $\ldots \ldots \ldots \ldots$ & $\ldots \ldots \ldots$ & 22 & 37 \\
\hline & . AGCTACATCTG & gGCTACTgG..... & ............ & ......... & 19 & 2 \\
\hline 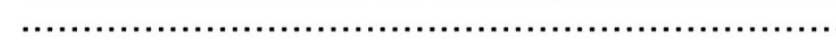 & .AGCTACATCTG & gGCTACTGGGTCto & TtGa......... & ......... & 27 & 2 \\
\hline & 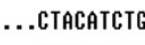 & gGCTACTGGGTсо & т........... & $\ldots \ldots \ldots$ & 23 & 1 \\
\hline & ....СТАСатсть & gGCtactggGtcto & ............. & ......... & 22 & 1 \\
\hline (n.................................. & ..... TACATCtG & gGctactggGtcto & ,............ & ......... & 21 & 1 \\
\hline
\end{tabular}

0.38 to 2.45 . Using the MFEI cutoff value of $0.97,22$ novel miRNAs present in the two libraries were identified (Table 3). Expression of these new miRNAs was typically several to a hundred counts lower than conserved miRNAs.

\section{Discussion}

Studies on expression and function of miRNAs in evolutionarily diverse agricultural species are limited. The alpaca is a domestic mammal specialized in fiber production [39] and has more than 22 natural coat colors [40-44]. In this report, we explored the miRNA transcriptome in alpaca skin using deep sequencing technology, and provided a foundation for future functional studies on the relationship between miRNA expression and development and function of skin including coat color.

Many miRNAs have been identified by traditional Sanger sequencing and microarray methods. However, the high throughout-sequencing method which yields 400,000 reads per run and identifies low abundance tags is a much more comprehensive method for miRNA profiling [45]. Using this sequencing approach, we found 22 novel, as well as 272 and 267 conserved miRNAs in WA and BA skin libraries [2]. According to the new miRNA family classifications in Rfam (miRBase 17.0), 272 miRNAs from WA and 267 miRNAs from BA were grouped into 155 families. Most of these identified miRNA families are also conserved in other 


\begin{tabular}{|c|c|c|}
\hline \multicolumn{3}{|l|}{ miR-3 6a } \\
\hline СTGTAAACATCCTCGACTGGAACTGTGAGGCTGCAGAAAGGCTTTCAGTCGGATGTTGCAGCTGC & $1 \mathrm{er}$ & cou \\
\hline $\begin{array}{l}\text {.TGTAAACATCCTCGACTGGAAG. } \\
\text {. }\end{array}$ & 22 & 1992 \\
\hline 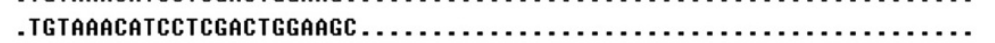 & 23 & 425 \\
\hline 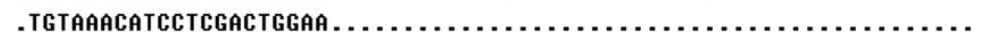 & 21 & 359 \\
\hline 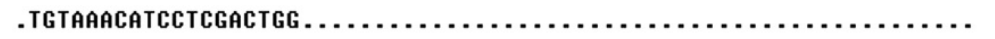 & 19 & 189 \\
\hline 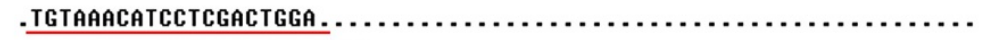 & 20 & 119 \\
\hline 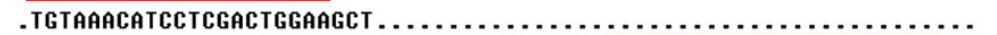 & 24 & 12 \\
\hline .................... . & 22 & 11720 \\
\hline 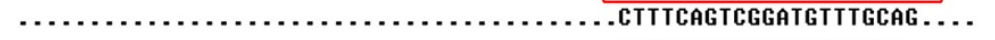 & 21 & 3718 \\
\hline 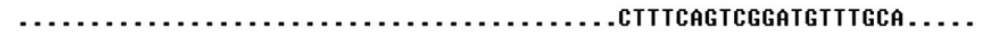 & 20 & 135 \\
\hline . . . . . . . . . & 19 & 55 \\
\hline 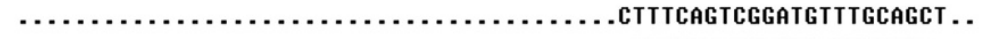 & 23 & 38 \\
\hline 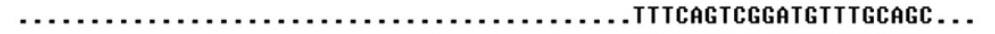 & 21 & 5246 \\
\hline .tTTCAgtCGgatgttTGCag. & 20 & 1744 \\
\hline
\end{tabular}

\section{$\operatorname{miR}-324$}

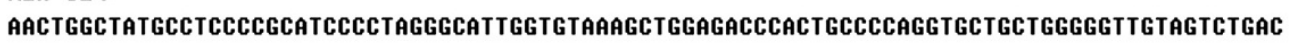

\begin{tabular}{|c|c|c|}
\hline 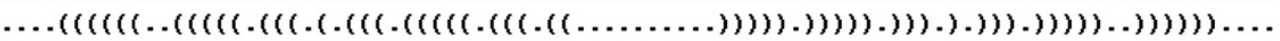 & len & cou \\
\hline . . . . . . . . . . & 22 & 13 \\
\hline 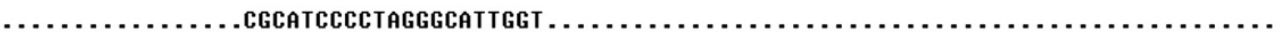 & 21 & 7 \\
\hline$\ldots \ldots \ldots$. . & 23 & 2 \\
\hline 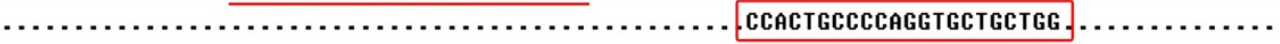 & 22 & 35 \\
\hline 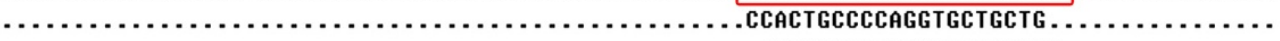 & 21 & 7 \\
\hline 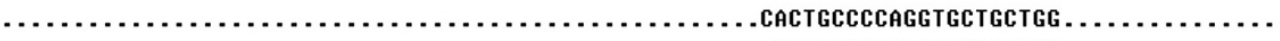 & 21 & 1 \\
\hline 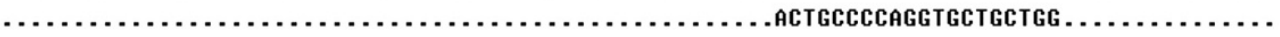 & 20 & 2 \\
\hline
\end{tabular}

\section{miR-330}

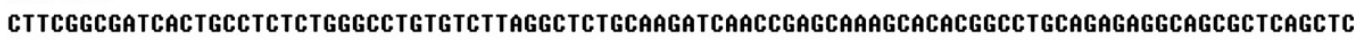

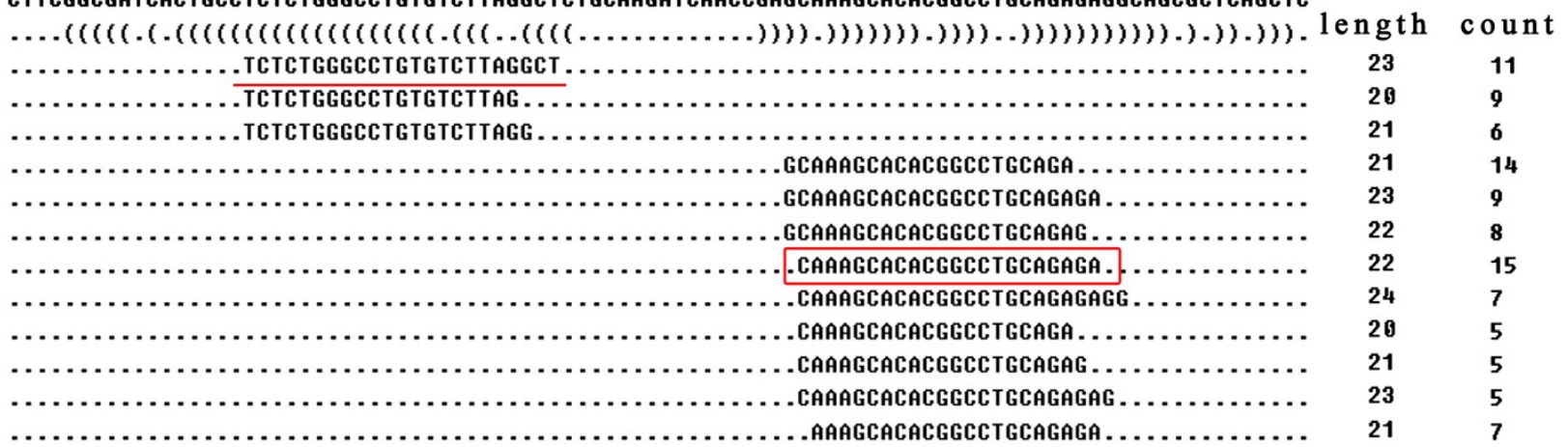

Figure 7 Annotated miRNA and maximal sequences from different arms of the precursors. The red underlined sequences are the annotated mature sequences in miRBase while the boxed sequences represent the maximum counts in sequencing database.

mammalian species, such as mouse [23,46], human [26], goat and sheep [22]. Expression of these conserved alpaca miRNA families differed between WA and BA skin, based on both abundance and representation within miRNA families. For example, miR-146 and miR-8 families both had abundant reads in WA and BA skin libraries, but miR-146b (miR-146 family) and miR-141 (miR-8 family) were of greater abundance in WA than BA. This significant variation maybe attributed to the timing and location of miRNA expression during skin development in adult alpacas. In many miRNA families, there was a predominant member whose reads

Table 2 Targets for top 4 significantly expressed miRNAs in white and brown alpaca involved in melanogenesis

\begin{tabular}{ll}
\hline Name & Predicted targets involved in melanogenesis \\
\hline miR-211 & CPNE8, PRKCG, TMEM135, ARMC8, DCT, PLCB1,WNT3 \\
miR-424* & GNAI2, TCF7, CREB3, FZD7, MYOF, PRKACB, KIT, GNAI1, PLCB1, SYT11, SYT1, MCTP1, FZD1, SYT4, CALM \\
miR-202 & CPNE8,TCF7, KRAS, WNT7A, PRKCB, KIT, CAMK2D, CABP2, EDNRB, WNT5A, FZD4 \\
miR-184 & CAMK2A, FAM193B, MYOF, ADCY5, ADCY8, PRKCB, PLCB3, RAF1, SYT1, WNT11, PRKACA, WNT16, PLCB2 \\
\hline
\end{tabular}


Table 3 Novel miRNAs identified in alpaca skin

\begin{tabular}{lll}
\hline Name & Sequence & MFEl \\
\hline Alpaca-novel-82 & TCGCTCTCCTGCTCGCTCTGC & 0.9789 \\
\hline Alpaca-novel-60 & TCTGGAGGACGCCGCTCGCGCTC & 0.9811 \\
\hline Alpaca-novel-56 & GAATGGTGCTCCCTGGAATTGT & 0.9974 \\
\hline Alpaca-novel-24 & AGGGAACCTTGAAAAGCTGAAG & 0.9986 \\
\hline Alpaca-novel-83 & CAGGACCTGGGGACACCATTGT & 1.0079 \\
\hline Alpaca-novel-37 & TGTTCTCAGAAGACTGTAGT & 1.0155 \\
\hline Alpaca-novel-17 & TGAACGGGGCCCTTCTGGTAG & 1.0246 \\
\hline Alpaca-novel-61 & CCTCACCTGTCATTCTCCCAGA & 1.0324 \\
\hline Alpaca-novel-31 & ATTGGCATGTCCTGGAATGAG & 1.0554 \\
\hline Alpaca-novel-53 & CCAAACCAGTTGTGCCTGTAG & 1.0602 \\
\hline Alpaca-novel-45 & ACTTGGATTTGAGTCTCTGGT & 1.1026 \\
\hline Alpaca-novel-8 & ACAAAGTTGGCTGCCTGTGAGC & 1.1197 \\
\hline Alpaca-novel-9 & TTGGTTGATACGTGGATGTGG & 1.1877 \\
\hline Alpaca-novel-33 & ATCCGTGGTTGGTGAATATGC & 1.2365 \\
\hline Alpaca-novel-32 & TGAATGGCACCTTATGAGTAGA & 1.2418 \\
\hline Alpaca-novel-76 & AACTCAGTGTCAGATAGGAAGA & 1.2434 \\
\hline Alpaca-novel-27 & TTAGTGATGTTGGTAAAAGAG & 1.3272 \\
\hline Alpaca-novel-44 & TCTGAAATTAAATGTAACCGG & 1.3920 \\
\hline Alpaca-novel-43 & TTGTTGTGGTTGATAGTATT & 1.5895 \\
\hline Alpaca-novel-68 & TAATAGGTGATCAAATGAATGA & 1.9358 \\
\hline Alpaca-novel-81 & ATTGATCTTGACTATAACTG & 2.0412 \\
\hline Alpaca-novel-8 & ACAAAGTTGGCTGCCTGTGAGC & 2.4490 \\
\hline
\end{tabular}

MFEl, MFE index.

were significantly higher than other members. For example, the Let- 7 miRNA family contains 10 members. The reads for let-7a were more than one million, but let$7 \mathrm{i}$ only had five thousand reads. It is possible that the predominant member in each miRNA was responsible for the regulatory role at the developmental stage in which skin samples were collected in the present studies.

We compared the expression of conserved miRNAs between WA and BA skin and identified differentially expressed miRNAs from the two libraries. The expression of miRNAs has an established relationship with cell proliferation and differentiation. As such, differences in miRNA expression between animals possibly reflect alterations in growth and differentiation. Heterochrony, or change in the timing of developmental growth, is known to alter the overall shape of developing tissues, leading to differences in physiology [47]. Alternatively, there are pronounced phenotypic differences between WA and BA which include fiber diameter, staple length, hair color and other hair characteristics [48,49]. Thus, differences in miRNA abundance may also be related to hair color and other fiber characteristics. The functional role of such differentially expressed miRNAs is the focus of future investigation.

In animals, miRNAs target mRNAs with partial sequence complementarity [50]. One miRNA is inferred to influence expression of hundreds of mRNAs via this flexible recognition. There were many differentially expressed miRNAs identified between WA and BA skin, so the next step was to search for putative specific genes targeted by these miRNAs. The major physiological difference of interest between the samples analyzed was coat color, so we focused on potential target genes regulating pigmentation. Based on KEGG pathway analysis, we found 117 potential miRNA target genes involved in melanogenesis. Many miRNAs targeting these genes have been reported. For examples, miR-137 [51] and miR-25 [28] were previously shown to regulate the expression of MITF, which is an important regulator of melanocyte growth, maturation, apoptosis and melanogenesis. In the present study, miR-137 and miR-25 were found in both libraries and their target genes also included MITF. Haflidadóttir et al. showed that miR-148 affects Mitf mRNA expression in melanoma cells through a conserved binding site in the 3'-UTR sequences of mouse and human Mitf [52]. In our studies, miR-148 showed greater expression in WA versus BA. So, it is possible that miR-148 may contribute to coat color differences between WA and BA.

The present studies also revealed that both miR-193a and miR-193b are differentially expressed in WA and BA skin. Gao et al. reported that Kit expression was subject to post-transcriptional regulation by miR-193a and miR-193b in human acute myeloid leukemia [53,54]. In humans, Kit contributes to the regulation of skin pigmentation [55] and we have previously reported Kit expression is higher in skin of BA versus WA [34]. Thus, miR-193a and miR$193 \mathrm{~b}$ may play a role in coat color determination in alpacas via regulating the expression of Kit.

\section{Conclusions}

Studies reported provide novel information on miRNA expression in alpaca species, including conserved miRNAs and potential novel miRNAs, and insight into differential miRNA expression associated with coat color and respective target genes. The predicted targets of the conserved miRNAs include 117 genes related to melanogenesis. Further validation of the functional role of differentially expressed miRNAs and their targets will provide better understanding of the miRNA regulatory mechanisms influencing coat color.

\section{Methods}

\section{Sample collection and total RNA extraction}

Housing and care of alpacas and collection of skin samples for use in described experiments were conducted in accordance with the International Guiding Principles for Biomedical Research Involving Animals (http://www. cioms.ch/frame 1985 texts of guidelines. html). Three white and three brown healthy adult alpaca (lama paco) 
were selected from the alpaca farm in Shanxi Agriculture University (Shanxi, China) for sample collection. Three pieces of skin $(2 \mathrm{~cm} \times 3 \mathrm{~cm})$ from the hindquarter were collected under local anesthesia and immediately stored in liquid nitrogen. Total RNA from the samples was extracted using Trizol reagent (Invitrogen, Carlsbad, CA, USA) according to the manufacturer's instructions. The RNA integrity was evaluated by gel electrophoresis and the RNA concentration was measured by OD260 reading using a Nanodrop spectrophotometer.

\section{Small RNA library preparation and sequencing}

For deep sequencing, total RNA samples were sizefractionated on a 15\% PAGE gel, and the 16-30 nt fraction was collected. The 5'RNA adaptor and 3'RNA adaptor were ligated to the RNA pools, and the RNAs of 64-99 nts were isolated through gel elution and ethanol precipitation. PCR products were purified and small RNA libraries were sequenced using Illumina Genome Analyzer. Sequencing was carried out at the ShenZheng Genomics Institute (BGI, China).

\section{Initial processing of reads and identification of conserved miRNAs}

Raw sequence reads were produced by the Illumina HiSeq2000 and processed into clean full length reads by the BGI small RNA pipeline. During the procedure, all low quality reads, including $3^{\prime}$ and 5' adapter contaminants were removed. The remaining high quality sequences larger than 30nt and smaller than 18nt were discarded. Then, all high quality sequences were mapped to Vicugna pacos genome (http://www.ncbi.nlm.nih.gov/nuccore/206581138) and Bos Taurus genome (http://hgdownload.cse.ucsc.edu/ goldenPath/bosTau4/bigZips/bosTau4.fa.gz) by SOAP [56]. All clean reads were compared with the sequences of non-coding RNA (rRNA, tRNA, snRNA, snoRNA) available in Rfam (http://www.sanger.ac.uk/software/Rfam) [57] and the GenBank non-coding RNA database (http:// www.ncbi.nlm.nih.gov/) to classify degradation fragments of non-coding RNA. We followed the rule [58]: rRNAetc, in which Genbank > Rfam > known miRNA > repeat > exon > intron. Subsequently, the remaining sequences were aligned to the whole animal miRNAs deposited in miRBase 17.0 to obtain the known miRNAs in alpaca as well as base bias at the first position of identified miRNAs and at each position of all identified miRNAs respectively. If a known miRNA in alpaca showed homology with less than two mismatches (or $>90 \%$ homology), it was considered as evolutionary conserved.

\section{Validation of conserved miRNA expression}

Ten conserved miRNAs were selected for validation by quantitative real time PCR analysis. Total RNA was isolated from eight alpaca skin samples ( 4 brown, 4 white).
One $\mu \mathrm{g}$ of DNase-treated RNA was converted to cDNA using specific stem-loop RT primer (Additional file 5) and HiFi-MMLV cDNA kit mix (CWBIO, Beijing, China). The cDNA was then used for real time PCR quantification of miRNAs using miRNA specific primers (Additional file 5) in combination with the universal primer. U6 snRNA was used as an endogenous control (primers listed in Additional file 5). Quantitative realtime PCR was performed in triplicate on the Stratagene Mx3005P system. The $25 \mu \mathrm{L}$ PCR reaction included 12.5 $\mu \mathrm{L}$ SYBR Premix Ex Taq ${ }^{\mathrm{TM}}$ II (TaKaRa, Dalian, China), $1.0 \mu \mathrm{L}$ specific forward primer, $1 \mu \mathrm{L}$ universal primer, $0.5 \mu \mathrm{L}$ ROX reference dye, $2.5 \mu \mathrm{L}$ diluted (4 times) cDNA and $7.5 \mu \mathrm{L}$ water. Cycling parameters were $95^{\circ} \mathrm{C}$ for $30 \mathrm{sec}$ followed by 40 cycles of $95^{\circ} \mathrm{C}$ for $5 \mathrm{sec}, 56^{\circ} \mathrm{C}$ or $58{ }^{\circ} \mathrm{C}$ for $20 \mathrm{sec}$ and $72{ }^{\circ} \mathrm{C}$ for $15 \mathrm{sec}$. Melting curve analyses were performed following amplifications. Quantification of selected miRNA transcript abundance was performed using the comparative threshold cycle (CT) method established by Livak et al. [59]. The abundance of selected miRNAs was normalized relative to that of U6 snRNA [60].

\section{Identification of novel miRNAs}

The prediction of alpaca candidate novel miRNAs was conducted using criteria that were previously developed for animal miRNA prediction [61]. The criteria were as follows: the putative mature sequence must reside at the stem region and its size was limited to 20-24nt; the frequency of putative mature sequence should not be below 5 ; the folding free energy of the stem-loop structure was limited to below $-18 \mathrm{kcal} \mathrm{mol}^{-1}$; the maximum tolerance of a bugle size was 4 nucleotides; the maximum size of difference between miRNA and miRNA* was 5 nucleotides and 35 nucleotides; the sequence asymmetry between miRNA and miRNA* could not exceed 5 nucleotides. The selected sequences were then folded into a secondary structure using mFold3.2 (http://mfold. rit.albany.edu). If a perfect stem-loop structure was formed, the small RNA sequence was located at one arm of the stem and met the above criteria, the small RNA was then considered as a candidate novel alpaca miRNA. The formula for calculating MFEI was: MFEI $=[($ MFE / length of the RNA sequence) $\times 100] /(\mathrm{G}+\mathrm{C}) \%]$.

\section{Target gene prediction}

Mireap software (https://sourceforge.net/projects/mireap/) was used to predict the target genes for conserved miRNAs identified. The criteria were as follows: no more than four mismatches between miRNA \& target (G-U bases count as 0.5 mismatches); no more than two adjacent mismatches in positions $2-12$ of the miRNA/target duplex $\left(5^{\prime}\right.$ of miRNA); no mismatches in positions 10-11 of miRNA/ target duplex; no more than 2.5 mismatches in positions 
1-12 of the miRNA/target duplex ( $5^{\prime}$ of miRNA); MFE of the miRNA/target duplex should be $>75 \%$ of the miRNA bound to its perfect complement.

\section{Additional files}

Additional file 1: Table S1. Heterogeneity at the $5^{\prime}$ and $3^{\prime}$ ends of the sequenced reads. The list of alpaca miRNAs different with miRNAs in miRBase based on sequencing counts.

Additional file 2: Table S2. Gene Ontology analysis of miRNAs targets. Targets of conserved miRNAs were grouped by Gene Ontology.

Additional file 3: Table S3. Novel miRNAs in white and brown alpaca skin. Sequences and MFE of candidate novel miRNAs in white and brown alpaca.

Additional file 4: Structure S4. Stem-loop structure of novel miRNAs. The stem-loop structure of 87 novel miRNAs in white alpaca and brown alpaca. The red underlined sequences are the predicted mature sequences

Additional file 5: Table S5. miRNAs primers for real time PCR. List of miR-202, miR-211, miR-27a, miR-200a, miR-193b, miR-423 miR-484, miR205, miR-137, miR-145 and U6 specific stem-loop RT primer, specific primers and universal primer.

\section{Abbreviations}

miRNAs: MicroRNAs; WA: White alpaca; BA: Brown alpaca; sRNA: Small RNA; sncRNA: Small endogenous non-coding RNA; MC1R: Melanocortin-1 receptor; ASIP: Agouti signaling protein; TYRP1: Tyrosinase related protein 1; TYR: Tyrosinase; TYRP2: Tyrosinase related protein 2; NOS2: Nitric oxide synthase 2; PAX3: Paired box protein 3; MFE: Minimum free energy; MFEl: MFE index; MITF: Microphthalmia-associated transcription factor; POMC: Pro-opiomelanocortin; MSH: Melanocyte-stimulating hormones; KIT: Kit oncogene.

\section{Competing interests}

The authors declare that they have no competing interests.

\section{Authors' contributions}

$X T$ designed the study, performed the analysis, analyzed the data and wrote the paper. JBY and GWS participated in the design of the study, analyzed the data and critically revised the manuscript. DLZ and YFS took part in collecting samples and the data analysis. JBJ, RWF, HDW, XLM, XYH, JPH, $H Q L$, JJG and XJY conceived of the study and critically revised the manuscript. CSD participated in the design of the study, analyzed the data and participated in writing. All authors read and approved the final manuscript.

\section{Acknowledgements}

We thank Dr. Xinmin Li (Department of Pathology \& Laboratory Medicine, David Geffer School of Medicine, UCLA), professor Lihua Lü, Yun Zhang for useful advice, discussion, and assistance and Mr. Wang Ying (China alpaca farm, Zhuangzi, Yuci, China) for providing experimental animals. The study was sponsored by the National Natural Science Foundation of China (30571070, 2006031060)

\section{Author details}

${ }^{1}$ College of Animal Science and Technology, Shanxi Agricultural University, Taigu 030801, People's Republic of China. 'Division of Animal and Nutritional Sciences, Laboratory of Animal Biotechnology and Genomics, West Virginia University, Morgantown, WV 26506, USA. ${ }^{3}$ Laboratory of Mammalian Reproductive Biology and Genomics, Departments of Animal Science and Physiology, Michigan State University, East Lansing, MI 48824, USA.

Received: 9 April 2012 Accepted: 8 October 2012

Published: 16 October 2012

\section{References}

1. Fire A, Xu SQ, Montgomery MK, Kostas SA, Driver SE, Mello CC: Potent and specific genetic interference by double-stranded RNA in Caenorhabditis elegans. Nature 1998, 391(6669):806-811.

2. Carthew RW, Sontheimer EJ: Origins and Mechanisms of miRNAs and siRNAs. Cell 2009, 136(4):642-655.

3. Grivna ST, Beyret E, Wang Z, Lin H: A novel class of small RNAs in mouse spermatogenic cells. Gene Dev 2006, 20(13):1709-1714.

4. Bartel DP: MicroRNAs: Genomics, biogenesis, mechanism, and function. Cell 2004, 116(2):281-297.

5. Li LC, Pookot D, Noonan EJ, Dahiya R: MicroRNA-373 induces expression of genes with complementary promoter sequences. $P$ Natl Acad Sci Usa 2008, 105(5):1608.

6. Landgraf P, Rusu M, Sheridan R, Sewer A, lovino N, Aravin A, Pfeffer S, Rice A, Kamphorst AO, Landthaler M: A Mammalian microRNA expression atlas based on small RNA library sequencing. Cell 2007, 129(7):1401-1414.

7. He L, Hannon GJ: MicroRNAs: Small RNAs with a big role in gene regulation. Nat Rev Genet 2004, 5(7):522-531.

8. Barsh G, Cotsarelis G: How hair gets its pigment. Cell 2007, 130(5):779-781.

9. Ito S, Wakamatsu K, Ozeki $\mathrm{H}$ : Chemical analysis of melanins and its application to the study of the regulation of melanogenesis. Pigm Cell Res 2000, 13:103-109.

10. Ito S, Wakamatsu K: Chemistry of mixed melanogenesis-pivotal roles of dopaquinone. Photochem Photobiol 2008, 84(3):582-592.

11. Lamason RL: SLC24A5, a putative cation exchanger, affects pigmentation in zebrafish and humans. Science 2005, 310(5755):1782-1786.

12. Passeron T, Valencia JC, Bertolotto C, Hoashi T, Le Pape E, Takahashi K Ballotti R, Hearing VJ: SOX9 is a key player in ultraviolet B-induced melanocyte differentiation and pigmentation. P Natl Acad Sci Usa 2007, 104(35):13984-13989.

13. Chintala S: Slc7a11 gene controls production of pheomelanin pigment and proliferation of cultured cells. P Natl Acad Sci Usa 2005, 102 (31):10964-10969.

14. Feeley N, Munyard K: Characterisation of the melanocortin-1 receptor gene in alpaca and identification of possible markers associated with phenotypic variations in colour. Anim Prod Sci 2009, 49(8):675-681.

15. Bathrachalam C, Manna VL, Renieri C, Terza AL: Asip and MCIR CDNA polymorphism in alpaca. In Fibre production in South American camelids and other fibre animals; 2012:93-96.

16. Powell AJ, Moss MJ, Tree LT, Roeder BL, Carleton CL, Campbell E, Kooyman $\mathrm{DL}$ : Characterization of the effect of melanocortin 1 receptor, a member of the hair color genetic locus, in alpaca (Lama pacos) fleece color differentiation. Small Ruminant Res 2008, 79(2-3):183-187.

17. Hart KW, Barker SJ, Skerritt JW, Vercoe PE: The gene for white fleece in alpacas is homologous to AWt, the gene for white fleece in sheep. In 50 years of DNA: Proceedings of the Fifteenth Conference, Association for the Advancement of Animal Breeding and Genetics, Melbourne, Australia, 7-11 July 2003. 2003:82-85.

18. Feeley N, Bottomley S, Munyard K: Three novel mutations in ASIP associated with black. J Agr Sci 2011, 149:529-538.

19. Zdarsky E, Favor J, Jackson IJ: The molecular basis of brown, an old mouse mutation, and of an induced revertant to wild type. Genetics 1990, 126(2):443-449.

20. Rieder S, Taourit S, Mariat D, Langlois B, Guérin G: Mutations in the agouti (ASIP), the extension (MC1R), and the brown (TYRP1) loci and their association to coat color phenotypes in horses (Equus caballus). Mamm Genome 2001, 12(6):450-455.

21. Schmidt-Küntzel A, Eizirik E, O'Brien SJ, Menotti-Raymond M: Tyrosinase and tyrosinase related protein 1 alleles specify domestic cat coat color phenotypes of the albino and brown loci. J Hered 2005, 96(4):289-301.

22. Zhang WG, WU JQ, Li JQ, Midori Y: A subset of skin-expressed microRNAs with possible roles in goat and sheep hair growth based on expression profiling of mammalian microRNAs. OMICS: A Journal of Integrative Biology 2007, 11(4):385-396.

23. Andl T, Murchison EP, Liu F, Zhang Y, Yunta-Gonzalez M, Tobias JW, And CD, Seykora JT, Hannon GJ, Millar SE: The miRNA-processing enzyme dicer Is essential for the morphogenesis and maintenance of hair follicles. Curr Biol 2006, 16(10):1041-1049.

24. Bostjancic E, Glavac D: Importance of microRNAs in skin morphogenesis and diseases. Acta Dermatovenerol Alp Panonica Adriat 2008, 17(3):95. 
25. Yi R, Poy MN, Stoffel M, Fuchs E: A skin microRNA promotes differentiation by repressing 'stemness'. Nature 2008, 452(7184):225-229.

26. Sonkoly $E$, Wei $T$, Janson PCJ, Sääf $A$, Lundeberg $L$, Tengvall-Linder $M$, Norstedt G, Alenius H, Homey B, Scheynius A: MicroRNAs: novel regulators involved in the pathogenesis of psoriasis? PLoS One 2007, 2(7):e610.

27. Dong C, Wang H, Xue L, Dong Y, Yang L, Fan R, Yu X, Tian X, Ma S, Smith GW: Coat color determination by miR-137 mediated down-regulation of microphthalmia-associated transcription factor in a mouse model. RNA 2012, 18:1679-1686.

28. Zhu Z, He J, Jia X, Jiang J, Bai R, Yu X, Lv L, Fan R, He X, Geng J: MicroRNA25 functions in regulation of pigmentation by targeting the transcription factor MITF in alpaca (Lama pacos) skin melanocytes. Domest Anim Endocrin 2010, 38(3):200-209.

29. Sand M, Gambichler T, Sand D, Skrygan M, Altmeyer P, Bechara F: MicroRNAs and the skin: Tiny players in the body's largest organ. J Dermatol Sci 2009, 53(3):169-175.

30. Allen E, Xie Z, Gustafson AM, Carrington JC: microRNA-directed phasing during trans-acting siRNA biogenesis in plants. Cell 2005, 121(2):207-221.

31. Schwab R, Palatnik JF, Riester M, Schommer C, Schmid M, Weigel D: Specific effects of microRNAs on the plant transcriptome. Dev Cell 2005, 8(4):517-527.

32. Jiang J, Yu X, He J, Dong C: Study on the expression and localization of tyrosinase in skin of alpacas with different coat colors. Scientia Agricultura Scinica 2010, 43(12):2555-2560.

33. Dong Y, Cao J, Wang H, Zhang J, Zhu Z, Bai R, Hao HQ, He X, Fan R, Dong $C$ : Nitric oxide enhances the sensitivity of alpaca melanocytes to respond to a-melanocyte-stimulating hormone by up-regulating melanocortin-1 receptor. Biochem Bioph Res Co 2010, 396(4):849-853.

34. Jiang J, Yu XJ, Tian X, He JP, Dong CS: SCF/c-KIT signal regulates the proliferation and division of alpaca (lama pacos) hair follicle melanocytes and its mechanism. Acta Anatomica Sinica 2011, 42(1):99-103.

35. Ren Y, Ren B, Fan R, Zhu Z, Yang Y, Li H, Dong C: Cloning and Expression Level Analysis of MC1R Gene in Alpacas with Different Coat Color. Acta Veterinaria et Zootechnica Sinica 2009, 40(6):5.

36. Lagos-Quintana M, Rauhut R, Lendeckel W, Tuschl T: Identification of novel genes coding for small expressed RNAs. Science 2001, 294(5543):853.

37. Bonnet $E$, Wuyts J, Rouzé $P$, Van de Peer $Y$ : Evidence that microRNA precursors, unlike other non-coding RNAs, have lower folding free energies than random sequences. Bioinformatics 2004, 20(17):2911-2917.

38. Zhang B, Pan X, Cox S, Cobb G, Anderson T: Evidence that miRNAs are different from other RNAs. Cell Mol Life Sci 2006, 63(2):246-254.

39. Cecchi T, Valbonesi A, Passamonti P, Gonzales M, Antonini M, Renieri C: Quantitative variation of melanins in alpaca (Lama pacos L.). Ital J Anim Sci 2011, 10(3):e30

40. McGregor B: Production, attributes and relative value of alpaca fleeces in southern Australia and implications for industry development. Small Ruminant Res 2006, 61(2-3):93-111.

41. Hoffman E: The complete alpaca book, 2nd edn. Santa Cruz, California: Bonny Doon Press; 2006

42. Lauvergne JJ, Marinez G, Ayala C, Rodriguez T: Supreme-Project: Identification of a primary population of South American domestic camelids in the province of Antonio Quijarro and Enrique Baldivieso (Department of Botosi, Bolivia) using the phenotypic variation of coat colour. In Progress in South American camelids Reasearch. Edited by Gerken M, Renieri C. The Netherlands: Wageningen Pers; 2001:64-74.

43. Bartolomé E, Sánchez MJ, Peña F, Horcada A: Testing objective metrics for the differentiation of coat colours in a Spanish alpaca population. In Fibre production in South American camelids and other fibre animals. Edited by Pérez-Cabal MÁ, Gutiérrez J, Cervantes I, Alcalde MJ. The Netherlands: Wageningen; 2011:79-86

44. Fan $R$, Yang G, Dong C: Study of hair melanin in various hair color Alpaca (Lama pacos). Asian Austral J Anim Sci 2010, 23:444-449.

45. Shendure J, Ji H: Next-generation DNA sequencing. Nat Biotechnol 2008 , 26(10):1135-1145

46. Yi R, O'Carroll D, Pasolli HA, Zhang Z, Dietrich FS, Tarakhovsky A, Fuchs E: Morphogensis in skin is governed by a discrete sets of differentially expressed microRNAs. Nat Genet 2006, 38(3):356-362.

47. Ason B, Darnell DK, Wittbrodt B, Berezikov E, Kloosterman WP, Wittbrodt J, Antin PB, Plasterk RHA: Differences in vertebrate microRNA expression. P Natl Acad Sci Usa 2006, 103(39):14385-14389.
48. McGregor BA, Butler KL: Sources of variation in fibre diameter attributes of Australian alpacas and implications for fleece evaluation and animal selection. Aust J Agr Res 2004, 55:433-442.

49. Lupton C, McColl A, Stobart R: Fiber characteristics of the Huacaya alpaca. Small Ruminant Res 2006, 64(3):211-224

50. Karginov FV, Conaco C, Xuan Z, Schmidt BH, Parker JS, Mandel G, Hannon GJ: A biochemical approach to identifying microRNA targets. P Natl Acad Sci Usa 2007, 104(49):19291-19296.

51. Bemis LT, Chen R, Amato CM, Classen EH, Robinson SE, Coffey DG, Erickson PF, Shellman YG, Robinson WA: MicroRNA-137 targets microphthalmiaassociated transcription factor in melanoma cell lines. Cancer Res 2008, 68(5):1362-1368.

52. Haflidadóttir BS, Bergsteinsdóttir K, Praetorius C, Steingrímsson E: miR-148 regulates Mitf in melanoma cells. PLoS One 2010, 5(7):e11574.

53. Gao X, Lin J, Gao L, Li Y, Wang L, Yu L: MicroRNA-193b regulates c-Kit proto-oncogene and represses cell proliferation in acute myeloid leukemia. Leukemia Res 2011, 35(9):1226-1232.

54. Gao X, Lin J, Li Y, Gao L, Wang X, Wang W, Kang H, Yan G, Wang L, Yu L: MicroRNA-193a represses c-kit expression and functions as a methylation-silenced tumor suppressor in acute myeloid leukemia. Oncogene 2011, 30(31):3416-3428.

55. Kasamatsu S, Hachiya A, Higuchi K, Ohuchi A, Kitahara T, Boissy RE: Production of the soluble form of KIT, s-KIT, abolishes stem cell factorinduced melanogenesis in human melanocytes. J Invest Dermatol 2008, 128(7):1763-1772.

56. Li R, Li Y, Kristiansen K, Wang J: SOAP: short oligonucleotide alignment program. Bioinformatics 2008, 24(5):713-714

57. Griffiths-Jones S, Moxon S, Marshall M, Khanna A, Eddy SR, Bateman A: Rfam: annotating non-coding RNAs in complete genomes. Nucleic Acids Res 2005, 33(suppl 1):D121-D124

58. Calabrese JM, Seila AC, Yeo GW, Sharp PA: RNA sequence analysis defines Dicer's role in mouse embryonic stem cells. P Natl Acad Sci Usa 2007, 104(46):18097-18102.

59. Livak KJ, Schmittgen TD: Analysis of relative gene expression data using real-time quantitative PCR and the $2^{-\Delta \Delta C T}$ method. Methods 2001, 25(4):402-408

60. Choong ML, Yang HH, McNiece I: MicroRNA expression profiling during human cord blood-derived CD34 cell erythropoiesis. Exp Hematol 2007, 35(4):551-564.

61. Berezikov E, Cuppen E, Plasterk RHA: Approaches to microRNA discovery. Nat Genet 2006, 38(6s):S2-S7.

doi:10.1186/1471-2164-13-555

Cite this article as: Tian et al:: Identification and characterization of microRNAs in white and brown alpaca skin. BMC Genomics 2012 13:555

\section{Submit your next manuscript to BioMed Central and take full advantage of:}

- Convenient online submission

- Thorough peer review

- No space constraints or color figure charges

- Immediate publication on acceptance

- Inclusion in PubMed, CAS, Scopus and Google Scholar

- Research which is freely available for redistribution 